\title{
EL UNIVERSO AXIOLÓGICO *
}

Miguel Bueno

Instituto de InVEstigaciones FLLosóficas Universidad Nacional Autónoma dE MÉxico

\section{Los cuatro universos}

1. Planteamientos básicos. De lo que hemos dicho se desprende la explicación de por qué cada uno de los problemas fundamentales que señalamos como constitutivos de la experiencia exhibe la formación del universo respectivo, el cual figura como fundamento del sistema que cada caso maneja. A partir de la concordancia imperante en planteamientos especificos, precisados en función de alcance universal, abordaremos un ensayo perspectivista de interpretación historiogénica, por el cual se aplica la idea de universo a problemas básicos que se han registrado de manera evolutiva a través de la historia $y$, según nuestro criterio, son en número de cuatro; para efecto de la exposición, distinguiremos sustancialmente la presencia de cuatro mundos o universos, el último de los cuales corresponde a la axiología. El motivo de esta precisión estriba en que el concepto universal del valor es culminante y tardío, pues aparece al final del derrotero histórico; se incluyen los demás a título prelativo y denotan la gestación sucesiva e integrativa del valor por cuanto exponen pasos constitutivos para la integración temática del universo axiológico, según el alcance aporético de sus respectivos conceptos. Así se advierten los siguientes

\author{
PLANTEAMIENToS bÁsicos dE LA FILOSOfía \\ (Mundos o universos) \\ a) Natural o cosmológico \\ b) Racional o epistemológico \\ c) Cultural o antropológico \\ d) Vital o axiológico
}

- Capítulo II del libro en preparación Tratado de Axiologia, $2^{a}$ Parte. La $1^{\text {a }}$ fue publicada en Diánoia, 1981. 
El orden en que se mencionan señala factor creciente de evolutividad y complejidad, involucrando al mismo tiempo un gradiente de fundamentación conceptual y estructural; la huella de sucesión indica que el planteamiento generado en el universo cosmológico o mundo natural asciende al universo epistemológico o mundo racional, incide en el universo antropológico o mundo cultural y culmina en el universo axiológico o mundo vital. Este último engloba a los demás, desde el momento que posee con respecto a ellos superior facultad explicativa y permite interpretarlo como el más complejo de todos, el que reviste mayor amplitud para la definición y comprensión de los problemas básicos de la filosofía. Asi se explica por qué el tema medular de nuestra disciplina demoró tanto tiempo en producirse de manera expresa, y por qué también demora el surgimiento de la axiología como disciplina autónoma, pues lo primero equivale a lo segundo; el universo axiológico se reconoce como problema sustantivo del filosofar desde el momento que su excogitación permite presentar a la axiología como disciplina filosófica de validez autónoma.

Lo más importante en estas observaciones estriba en obtener la consecuencia derivada de reconocer que el concepto de universo no denota necesariamente el mundo físico de la naturaleza, sino representa de manera más amplia universo conceptual, equivalente a noción fincada sobre el contenido de experiencia en el sentido que ya explicamos; también se puede llamar mundo si aplicamos un enfoque análogo que tampoco lo reduce al mundo físico; por ello, todo planteamiento filosófico es por sí universal y reposa en un mundo o universo, es decir, en un concepto totalizante que incluye la noción genérica de universo como algo externo e interno, cuya correlación se produce en el que llamamos en sentido estricto mundo de experiencia, equivalente al que se entiende como universo de vida humana.

2. Evolución del planteamiento. La evolución que asume el concepto de universo a través del tiempo se encuentra motivada desde las primeras reflexiones en torno a la noción del ser, tal como se expone en diversas tesis ontológicas que acoge el período cosmológico de la filosofía griega, las cuales son relativizadas por conducto del conocer en subsecuente periodo antropológico. No en balde advirtieron los eléatas, al primer arranque de critificación doctrinaria, que cualquier hipótesis ontológica o cosmológica se refiere a un aspecto parcial de la realidad y constituye idea del ser; por consiguiente, debe ser fundada, relativizada y critificada mediante la doctrina general de las ideas, lo cual ocurre desde Sócrates y Platón. A partir de los atenienses se implanta la primera exégesis verdaderamente sistemática del problema mediante el arraigo en la doctrina antropológica universal como principio de critificación, y 
también se inicia el tránsito del universo cosmológico al epistemológico, señalando el umbral de evolución multisecular que registra el concepto de universo a partir de las acepciones más elementales, ocurriendo al estado de madurez que se contempla en la integración de filosofía y cultura.

El siguiente paso en la progresión jerárquica del planteamiento se registra del segundo universo al tercero, o sea del epistemológico al antropológico, del mundo racional al mundo cultural, cuyo tránsito está connotado por multitud de doctrinas que se preocupan por la cultura y exhiben mayor desarrollo en la época moderna debido a la madurez adquirida por las doctrinas científicas relativas al hombre y los estudios que se refieren a sus productos, radicados tanto en la cultura misma como en civilización y vida cotidiana. Por último, el ascenso del universo antropológico o mundo cultural al universo axiológico o mundo vital, está significado por el surgimiento de autoconciencia metodológica que ocurre en la filosofía contemporánea, cuyo signo de integración se origina en el tránsito de la cultura a procesos que la explican, principios que la justifican y valores que la promueven.

El mundo vital o universo axiológico encarna al objeto y fundamento sustancial de la axiología, asumida bajo la modalidad expresa de filosofía de la cultura o filosofía de los valores y proseguida en ciencias particulares que también acometen problemas de valor; a través de ella puede y debe interpretarse el planteamiento axiológico en calidad implícita de problema integral, reflejado en la experiencia totalizante de la cultura; por ello engloba también al universo antropológico, pues incluye la obra representativa de lo humano, así como el mundo racional o epistemológico se refleja en el mundo natural o universo ontológico, desde el momento que los seres de la realidad se contemplan a través del conocimiento. Se comprende entonces que, debido a su mayor complejidad, el problema axiológico hubiese necesitado más tiempo para obtener la correcta formulación de maduraz requerida en términos expresos de planteamiento universal y solución también universal que son exigibles para el surgimiento de una doctrina filosófica.

3. Los cuatro conceptos. Cada uno de los cuatro mundos o universos admite un problema sustantivo que se funda en concepto básico, el cual explica su razón constitutiva como universo. El cosmológico se proyecta en el ser, mientras el epistemológico se desarrolla en el conocer, el antropológico se traduce en el hacer, y la realidad que totaliza la genealogía universal determina el vivir. De ahí que las nociones inherentes al problema axiológico se apliquen en última instancia a la explicación de la vida como fuente directa para el desarrollo de la cultura; a través de ella podemos percibir, explicar y asimilar el mundo que nos rodea. Todo 
esto se expresa escuetamente en la secuencia integrativa de los siguientes conceptos básicos:

$$
\text { Ser }+ \text { Conocer }+ \text { Hacer }+ \text { Vivir }=\text { Valer }
$$

Al proyectar la clasificación de los cuatro mundos o universos en axiomas postulatorios se obtiene la relación analógica y comparativa que exhibe la armónica disposición de los principios aporéticos frente a los mundos o universos respectivos.

\begin{tabular}{lll}
\hline Mundos & Principios & Universos \\
\hline Natural & Ser & Cosmologico \\
Racional & Conocer & Epistemológico \\
Cultural & Hacer & Antropológico \\
Integral & Vivir & Axiológico \\
\hline
\end{tabular}

Esos son los cuatro estratos determinativos del problema filosófico y acogen polaridades homólogas a través de planteamientos registrados en la historia; se postula al mundo o universo que es dable concebir de acuerdo al axioma intrínseco, en tal forma que se incorporan elementos de índole similar en la unidad connotativa del universo respectivo; a ello se debe la correlación que exponemos y también la esencia común a modalidades que conllevan los conceptos de universo, alternativa o sucesivamente postulados en la historia; así, por universo cosmológico o mundo natural se entiende el conjunto de todos los seres físicos que existen en la naturaleza; el universo epistemológico o mundo racional incluye el conjunto de conocimientos producidos por el hombre; el universo antropológico o mundo cultural se extiende a actos y obras de la cultura; por último, el universo axiológico o mundo vital atañe a todas las entidades que se perciben a través de la experiencia, incidiendo en intereses vitales bajo la forma de valores o entidades axiológicas; su denominador común se encuentra en el concepto universal del valor y se vincula indisolublemente al concepto universal de mundo, vida, cultura, conocimiento y ser; la correlación fincada entre hombre y mundo es base para explicar la generación de los cuatro universos, de modo que el último y más amplio absorbe a los demás mediante la relación jerárquica que engloba motivaciones experienciales.

4. Relación jerárquica. La jerarquía que advertimos en la citada relación señala niveles universales generados en orden creciente de complejidad y capacidad explicativa, a cuyo efecto el universo cosmológico sub- 
siste como objeto de explicación para el universo epistemológico, desde el momento que los seres de la naturaleza son inteligibles por medio del saber; pero éste resulta englobado en el universo antropológico debido a que el conocimiento es proyección del espíritu en la vida cultural; el universo axiológico ocurre como culminación al término de la secuela y exhibe su más amplia dimensión constitutiva al mismo tiempo que la mayor facultad explicativa, según el orden teorético proseguido en su desarrollo; el conjunto de capacidades humanas se integra en el universo antropológico y adquiere plenitud mediante la dinámica que le confiere su realización como valor, análogamente a como el universo epistemológico se incorpora al antropológico y por su conducto incide también en el cosmológico.

La relación jerárquica que se establece entre los cuatro universos ha sido advertida en el tratadismo historiográfico, pues corresponde al ritmo natural de evolución; por medio de ella se procura determinado progreso en planteamientos evolutivos que, de otro modo, parecerían simples opciones de elección ideológica; nosotros creemos haber captado el mecanismo de incorporación sucesiva en problemas capitales de la filosofía y lo aplicamos como criterio básico a su interpretación histórica, susceptible de evaluar y revaluar a través del proceso que denominamos subsunción aporética, el cual nos ocupará posteriormente con detenimiento. Por ahora refrendamos la existencia de esos cuatro mundos o universos como resultado de la postulación tética que ocurre mediante correspondientes axiomas determinativos del sistema; el proceso en cuestión radica en la posibilidad de subsumir un principio en otro de mayor amplitud explicativa, aunque sean ambos universales, pues la subsunción se efectúa en el orden cualitativo y se justifica en aras del diversificado rango de amplitud que exhiben los planteamientos, conceptos y universos operantes en cada caso. De ahí resulta que seres de la naturaleza, conocimiento, civilización y cultura, incluyendo actos y obras producidos en la vida cotidiana, se justifican en la medida que auspician concepción y realización de valores como totalidad de vida. $Y$ tras la anterior aclaración daremos término a este capítulo procediendo a breve examen de los cuatro mundo o universos a que hicimos referencia.

5. El universo cosmológico. El primero de los universos que se perciben en orden de aparición histórica corresponde a objetos de la realidad conocida por antonomasia como naturaleza, o sea el que entendemos por mundo natural o universo cosmológico. Bajo esta denominación se comprende el conjunto de seres y objetos que normalmente llamamos cosas, y representan al mundo físico en calidad de objetos materiales; su posición prioritaria en el despunte histórico obedece a que tales objetos se brindan ostensiblemente a la experiencia por conducto de la sen- 
sibilidad o sensorialidad, ventana abierta por el sujeto a la percepción del mundo físico. Como es sabido, el planteamiento cosmológico se registra en relación al ser y denota la existencia de un ser universal y esencial bajo la múltiple apariencia fenoménica que se brinda en seres particulares de la realidad; a ello se debe que el universo cosmológico figure en el umbral de la filosofía griega y ocupe la atención de su primer período, que recibe precisamente el nombre de cosmológico, y también lo reciben de manera concomitante las hipótesis emitidas para explicar la esencia de la realidad.

Se cuenta en ellas la primera doctrina que registra la historia mediante la opinión expuesta por Tales de Mileto el afirmar que el ser es el agua. Pero el hecho de optar otros filósofos por diferentes elementos para acreditar su visión cósmica, eligiendo a tal efecto aire, fuego, tierra, etc, denota la imposibilidad de cifrar la esencia del cosmos en una de tales sustancias, con las contradicciones que se producen al ser adoptada alguna con preponderancia sobre las demás. La actitud consistente en sostener algún elemento de la naturaleza como esencia del universo cosmológico ha caído en desuso, a cambio de lo cual la filosofía se ampara en el trabajo de las ciencias para llegar al conocimiento universal mediante su ingente preocupación por vincular doctrinas especialmente en el dominio de las ciencias naturales.

La inquietud que se contempla ahora como sucedánea del período cosmológico tiende a establecer que la esencia del universo no puede ser objeto de lucubración metafísica, pues no se trata de postular tal o cual elemento como esencia constitutiva de la realidad, a partir de seres concretos o entidades que se perciben por vía sensitiva; su índole particular impide que se lleve a cabo la inferencia directa hacia el plano universal que presuponen tales hipótesis. Obviamente, el universo cosmológico existe y debe tener alguna esencia, lo cual significa que estaría constituido en último término por sustancia o elemento que hasta ahora desconocemos, o no conocemos de manera suficiente; en cierto modo, la teoría más extendida consiste en proclamar básicamente a la energía como elemento constitutivo del cosmos, y su explicación, insuficientemente lograda, se lleva a cabo por conducto de las ciencias más que de la filosofía.

El propósito inherente al planteamiento jónico se mantiene en términos generales, pero la profunda diferencia advertida con respecto al moderno planteamiento cientifico estriba en que no se trata ya de inventar o imaginar en qué consiste dicha esencia, sino de conocerla y explicarla, como se observa en las hipótesis expeditadas por conducto del trabajo científico. Así se infiere que la esencia del universo radica en la energía, de modo que sus diversas manifestaciones se estudian cada vez 
con mayor profundidad, pero aún no se llega a noción última e intrascendible que satisfaga el planteamiento tradicional y figure como origen para explicación de sus manifestaciones, de modo que pudiese connotar la existencia de un ser-en-sí o causa primera, un ser más allá del cual no pueda encontrarse otro ser, a la manera como concibieron los filósofos griegos. El planteamiento ontológico persiste como gran problema por resolver y constituye idea regulativa para el desarrollo de las ciencias, en medida que la noción del ser prevalece como prioritaria en orden de genealogía aporética, por cuyo efecto opera el proceso evolutivo que interesa resaltar; se trata del traslado al ámbito científico de planteamientos originalmente fincados en el campo filosófico, lo cual configura el proceso que nos ocupará más tarde bajo el rubro de metátesis aporética.

6. El universo epistemológico. Otro hecho decisivo que se constata desde la época clásica es el advenimiento de la filosoffa idealista; según ella, nos percatamos de la realidad a través del pensamiento y cada idea que emitimos sobre el ser es precisamente una idea del ser. Por tal efecto, lo que podamos decir en torno al ser comporta un conjunto de nociones cognitivas sobre el ser mismo, incluyendo el sistema de principios lógicos que condicionan al conocimiento; de este modo, una tesis cualquiera no puede interpretarse sustancialmente como atribución ontológica del ser-en-si, por el contrario, comporta la noción indeclinable del ser-en-mi o, lo que equivale, del ser-contemplado-a-través-del-conocimiento.

La gran aportación de la filosofía idealista consiste en afirmar que nos damos cuenta de los objetos en la medida que los conocemos; también postula que adquieren un sentido inteligible al formar parte de nuestro universo. Por ello, la filosofía idealista constituye la superación inmediata del realismo y representa la puerta de ingreso al universo epistemológico, que a la vez conduce al universo antropológico, instaurando al conocimiento del conocimiento como vía determinativa de la realidad; el apotegma del traslado aporético estriba en observar que cualquier idea del ser es precisamente una idea del ser, y cualquier conocimiento es precisamente un conocimiento, incluyendo al conocimiento del conocimiento. Esta observación parecerfa demasiado obvia si no fuera porque suele inadvertirse en doctrinas que, por afirmar la inmediatez del ser, soslayan la crucial inherencia del pensar. El contenido que justifica una afirmación aparentemente reiterativa se pone de manifiesto mediante el examen introspectivo que surge con la critica a la actitud realista y origina la doctrina filosófica derivada de la crítica, conocida precisamente como criticismo; de ahí provienen las posturas metodológicas y formales esencialmente críticas o racionales; la critica asimila el 
universo cosmológico al epistemológico, lo cual orilla a replantear el problema del ser en condiciones que fija el pensar. Persiste incólume el carácter básico de la correlación objeto-sujeto como representativa del vínculo entre mundo externo y mundo interno, con preponderancia de este último, de suerte que la relación entre ser y conocer induce a desplazar el centro de gravedad del primer elemento al segundo, con lo cual se instituye el origen de las posturas idealistas o racionalistas y también despunta su predominio histórico mediante la identidad parmenidea: ser es pensar.

La critificación introspectiva del idealismo se vincula a la tendencia complementaria, o sea la extrospectiva y conduce directamente al segundo universo que aparece en la evolución histórica, correspondiendo al conjunto de nociones intelectivas constituídas por ideas de la más variada índole que permiten explicar la naturaleza de los objetos pertenecientes al universo cosmológico. La necesidad de este segundo universo es obvia, desde el momento que sólo podemos entender lo que son las cosas si logramos conocerlas, y si no las conocemos nada significan para nosotros, ni siquiera el hecho de que se encuentren en la realidad. Para afirmar este principio debemos también acudir al conocimiento; el precitado apotegma del idealismo afirma que en requerimientos de constatación, comprensión y asimilación de la realidad, el pensar adquiere prioridad con respecto al ser, pues el pensamiento es parte entitativa de nosotros mismos. El reverso de la tesis indica que el soslayo de facultades intelectivas en captación de objetos equivale a ignorar que tales objetos existen para nosotros en medida que los conocemos; así se refrenda lo que dijimos anteriormente al reafirmar la tesis tradicional del idealismo en el sentido de que una idea del ser es una idea del ser y un conocimiento de cualquier objeto es un conocimiento de ese objeto; no se trata de emitir expresiones reiterativas sino de evitar que vuelva a proclamarse la idea-en-si, y tampoco el ser-en-si, pues en última instancia nada hay en-si, todo es en-algo, o lo que equivale, en-mi. Así se trascienden las posturas estáticas y dogmáticas que han existido, tanto en realismo como en idealismo, cuando se interpretan como absolutas, formuladas dogmáticamente sobre la realidad y percibidas unilateralmente mediante la sensorialidad.

Todo ello se comprende al surgimiento de la filosofía iclealista, cuyo principio indica que cada idea pronunciada en relación al ser representa una idea del ser; constituye este principio axioma insuperable en la filosofía de todos los tiempos y significa que el ser es conocido a través de ideas que comporta el conocimiento. La afirmación del universo epistemológico es sucedánea del cosmológico y su contenido realista se desenvuelve al socaire del idealismo, señalando nueva ascensión 
al plano explicativo del realismo crítico, que es en verdad una forma de idealismo, pues sólo el conocer es capaz de explicar al ser. De ahí se desprende la prioridad que adquiere el mundo intelectual en relación al mundo natural, y así como éste se presenta en su origen esgrimiendo la noción universal del ser, aquél incide en el concepto igualmente universal de la idea que, de este modo, adquiere prioridad definitiva sobre el ser, captado y asimilado como experiencia de la realidad naturaī.

7. El universo antropológico. En los anteriores conceptos se expone la tesis medular del idealismo, tal como es asumido en su modalidad crítica-epistemológica, y se enuncia la dependencia del ser con respecto al conocer; a su vez, el conocimiento constituye facultad distintiva del ser humano, pues en términos generales todos los hombres piensan, y en términos estrictos solamente los hombres piensan; el pensamiento se proyecta en la realidad como signo de esencia y existencia. Pero hay otras facultades anímicas cuya acción proyectiva en el mundo externo es similar a la que se contempla en el ámbito del pensamiento; mencionemos las que reconoce la filosofía tradicional, o sean básicamente sentimiento y voluntad, que constituyen, además de aquél, la base para configurar el primer sistema filosófico conducente al diseño del universo antropológico; su antecedente se encuentra en doctrina elaborada durante el segundo período de la filosofía griega, que por algo se conoce precisamente como periodo antropológico, pero su naturaleza de sistema representa la puerta de ingreso al periodo sistemático. La esencia de una filosofía fundada en convicción antropológica consiste en suponer que la naturaleza humana condiciona toda suerte de pensamientos, acciones y proyecciones del hombre sobre el mundo, incluido él mismo; de ahí que la doctrina antropológica adquiera sentido universal mediante la relación de hombre y mundo, como se expresa en el célebre aforismo protagórico: El hombre es la medida de todas las cosas.

La conformación del universo antropológico encuentra origen en ese apotegma e induce a integrar el conjunto de manifestaciones humanas que se reflejan en la naturaleza física, pero también reflejan la propia naturaleza y conducta del hombre, considerando al anthropos creador de su propio universo, condicionado primordialmente por el pensamiento, de análoga manera a como éste condiciona al ser; una conclusión que se asienta como fruto de concientización crítica sostiene que el conocimiento adquiere definitiva prioridad sobre las otras facultades del hombre: por medio del pensamiento nos percatamos de todo lo que existe; en ello radica el profundo nexo implantado entre los universos antropológico, epistemológico y ontológico, aunque la diferencia específica se encuentra en el intento que asume el primero al reconstruir la integralidad humana a partir de los desarrollos racionales promovidos 
por el segundo, cuya prevalencia a nivel cognitivo es inconmutable y se desenvuelve con materiales aportados a la experiencia por el tercero. El universo antropológico se refrenda como segunda etapa de subsunción aporética y justifica la observación de que, así como todo ser es una idea del ser, toda expresión de la naturaleza es expresión de la naturaleza humana; el universo epistemológico representa el producto del hombre y puede rastrearse para develar la esencialidad humana, en forma tal que invertimos el aforismo protagórico para hacer factible la afirmación de que: Todas las cosas son la medida del hombre. Esto significa que el hombre è asequible a través de las cosas que él mismo produce por medio de las facultades que lo constituyen, externadas a través de actos y obras en que se manifiesta.

8. El universo axiológico. La identidad establecida entre ser y pensar, por una parte, ser y hacer por otra, como representativa de subsunción epistemológica y antropológica, imbrica la relación de ambos términos frente al vivir y hace acto de presencia por la circunstancia de que tanto pensar como hacer, y a través de ellos el ser, constituyen manifestaciones de vida y determinan en calidad de expresiones antropológicas el contenido de experienecia. De este modo obtenemos una identidad más amplia y fecunda que se finca en cuatro postulados básicos de los universos respectivos; según ella, puede afirmarse a título concluyente que el ser se subsume en el pensar, análogamente a como éste se incluye en el hacer, que constituye un aspecto particular del vivir; finalmente, la subsunción integral ocurre en el valer, de modo que la participación de los valores como denominador genérico de ser, pensar, hacer y vivir, figura a manera de epílogo en el seno de la identidad correlativa de los planteamientos examinados. Esta secuencia aporética permite fincar la cuádruple ecuación que reviste el mayor significado en nuestra disciplina, de acuerdo a los términos que han sido expuestos.

\section{Ser es pensar, es hacer, es vivir y es valer}

La cobertura integral que atañe a los cuatro universos está cifrada en torno al valor y explica a qué obedecen número y variedad de modalidades que adquiere la realización de valores mediante la configuración del universo axiológico, entendido como planteamiento supremo de filosofía en su modalidad tética o material, de suerte que en ella se incluyen las esferas aporéticas que designamos como mundos o universos. Así se comprenden los objetos existentes en la naturaleza, captados a través del pensamiento, el cual recibe datos experienciales que proporciona la realidad: actos y obras que informan la cultura, experiencias que saturan la vida y correlaciones que desempeñan los respectivos intereses; todo 
ello desemboca en la noción universal del valor. El universo axiológico encarna el más fecundo de los principios que señalan la evolución de planteamientos universales en filosofía, fundada a partir de tesis materiales que se presentan como doctrinas explicativas de la realidad y exhiben la virtud necesaria para llevar a cabo la concepción totalizante del problema; esto significa que, así como el mundo natural resulta explicable a través del mundo intelectual, que a la vez queda englobado en el mundo cultural, la conjunción de todos sus principios se produce en el mundo vital, cuya capacidad de explicación y resolución frente a planteamientos básicos de la filosofía viene a ser dimensión máxima y por tal virtud subsume postulaciones anteriores.

El concepto universal de mundo y vida reconoce como punto de referencia el generalizado señalamiento de permanente correlación entre hombre y mundo, promovido a través de actos y obras que ocurren a la existencia. La vida humana, entendida como experiencia del valor, asimila el mayor alcance determinativo de rango universal de acuerdo a secuela integrativa de sus postulados y proporciona la clave para acceder a cosmopsicovisión axiológica. La experiencia que depara la vida humana en realización de finalidades se ve acompañada por conceptos que corresponden a entidades de todas clases que admiten la virtud de existir, pues sabemos que existencia equivale a experiencia, o sea la realidad determinada en y por la vida, que a la vez se entiende y extiende como generación del valor.

El universo axiológico representa así verificación del concepto universal del ser proyectado en los recodos de la realidad y momentos de experiencia; la acepción generalísima que reconocemos en el concepto de universo nos lleva a admitirlo como todo unificado en sus elementos y delimitado en alcance conceptual; ello permite afirmar la existencia de un universo en cada postura filosófica mediante el respectivo planteamiento básico, pues cada uno de los problemas fundamentales reposa en la correspondiente noción universal. El conglomerado de conceptos y sistemas, disciplinas y posturas que se advierten en filosofía, reserva a la axiología lugar primordial, a cuyo efecto enfatizamos que el concepto de valor se erige como el más amplio y comprehensivo de todos los conceptos universales que figuran a la base de doctrinas filosóficas. Obviamente no es el único, pero sí el más amplio y reciente, por cuanto el momento de constitución formal coincide con la madurez filosófica en vertiente material y traduce el alcance que revisten diversas significaciones axiológicas en la génesis tradicional de las doctrinas. De todo ello se desprende que, para ocupar el importante sitio que le corresponde en el marco de los planteamientos filosóficos, el universo axiológico debe ponerse en relación a sistemas que le preceden en orden de evo- 
lución genética, sobre los cuales recibe con toda propiedad la designación de mundo o universo.

\section{Civilización y cultura}

1. Preferencias, urgencias y apetencias. El examen que efectuamos en torno al origen y la evolución del valor demostró por modo elocuente que el surgimiento de las entidades axiológicas proviene de la más remota antigüedad y se encuentra bajo la forma de actos y obras que responden a necesidades o deseos, configurando la herencia acumulada por la humanidad a través de siglos y milenos. Ya señalamos de qué manera aparecen tanto deseos como necesidades en calidad de motivaciones experienciales, asumiendo respectivamente la índole de apetencias y urgencias. Los intereses denotan el origen del impulso requerido para el mantenimiento de la vida, correspondiendo a sendos hemisferios de lo humano: materia y espíritu. También sabemos que los deseos llegan a ser artificiales cuando inciden en requerimientos ficticios, lo cual nos remite al ciclo ontogénico del valor mediante un juego de tensiones y distensiones que corresponden a los variables estados de ánimo donde se refleja la diversidad de situaciones vitales.

Por tal virtud se promueve la dinámica existencial con la participación de necesidades y deseos vinculados al conjunto de intereses que se profesan en la vida, los cuales se insertan en la fenomenicidad de la experiencia y en la captación de la naturaleza. Ampliaremos ahora este análisis para explicar de qué manera se desarrollan las nociones implicativas del valor hasta alcanzar la extraordinaria magnitud que se constata en civilización y cultura, donde culmina el universo axiológico mediante la realización de toda suerte de valores. Necesario es remarcar la importancia que revisten ambas vertientes de la actividad como respuesta a la permanente producción de intereses o motivaciones, por cuyo efecto expondremos la dicotomía que se condensa en el siguiente esquema:

\section{MOTIVACIONES HUMANAS}

\section{Intereses o preferencias}

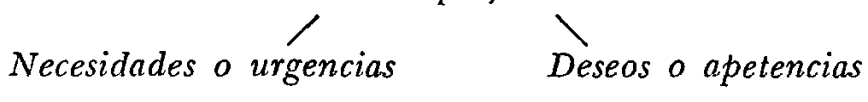

Podemos fundar las definiciones de esta clasificación como postulados básicos en el planteamiento del problema:

a) Intereses. Son elementos que suscitan una reacción en el ser humano y promueven actos que pueden ser de aceptación y posesión, o por el contrario, de negación y rechazo. 
b) Necesidades. Son intereses inmediatos que se presentan en la vida con carácter de urgencias y tienden a su preservación mediante el arbitrio de satisfactores vitales.

c) Deseos. Son intereses complementarios más elaborados que tienden a dignificar el progreso de la humanidad mediante elevadas satisfacciones de rango espiritual o cultural.

El denominador común de la actividad se localiza en el interés, o sea la motivación o atracción ejercida por diversos elementos que ingresan en la experiencia; los intereses se agrupan en dos grandes sectores, correspondiendo a las precitadas necesidades o urgencias y deseos o apetencias; motivan la predilección hacia el contenido que en ellos se manifiesta e incitan a la reacción positiva de poseerlos y contemplarlos, o la negativa de rechazarlos y evitarlos; en ambos casos se advierte un interés motivador, sólo que el primero exhibe signo positivo de atracción, mientras el segundo denota signo negativo de rechazo.

Las necesidades afloran en un principio para cumplir demandas básicas que plantea la vida, mientras los deseos constituyen una manifestación aleatoria y supletoria de la civilización, pues no se requieren estrictamente para asegurar la subsistencia biológica, sino provienen del juego intelectual o emocional sublimado en la cultura. El sugerente mundo de los deseos y la capacidad de alentarlos en forma progresiva prevalece sobre las necesidades, habida cuenta que su integración alcanza alto rango de complejidad mediante los frutos de la acción creadora, consagrada en el libre juego de aptitudes y actitudes que conducen a la suprema exaltación de creatividad espiritual.

2. Materia y espiritu. Estas observaciones derivan de lo ya expuesto sobre el origen del valor y constituyen la base para efectuar un análisis en torno a la vida humana entendida como universo axiológico polarizado básicamente en civilización y cultura, donde valores y experiencias se agitan constantemente con el impulso a producir cada vez mejores frutos a través de un prolongado esfuerzo que se renueva con el aliciente de progresar, en lo cual radica la motivación primigenia de vida.

Civilización y cultura se presentan indisolublemente unidas en la realidad, como materia y espíritu en la naturaleza humana; pero existe un distingo insoslayable y está cifrado en el carácter utilitario de la primera frente a la índole contemplativa de la segunda. Es evidente que actos tales como escribir un poema, componer una sinfonía, redactar una obra literaria, investigar en materia filosófica o científica, etc., constituyen expresiones intelectuales o espirituales y no se confundirán con la construcción de una carretera, la perforación de un pozo, el trazo de una ciudad o el montaje de maquinaria para la industria, aunque este tipo de actos realizan el gradiente intelectual involucrado en las disciplinas 
tecnológicas, de modo que todos los momentos o actos de la vida reflejan la humana creatividad. De cualquier forma, el requerimiento vital figura como aliciente, tanto en civilización como en cultura, auspiciando el desenvolvimiento del espíritu con el arbitrio de satisfactores materiales que configuran la acción práctica de la civilización, incluyendo los aspectos menores de la vida cotidiana. Cualquier ejemplo verifica la prevalencia del progreso entendido como mecanismo generador y receptor de valores, a cuya base figuran los conocimientos teóricos que aportan la más sensible contribución al desarrollo de la humanidad.

Existe una vasta zona de interacción recíproca donde se funden lo material y lo espiritual; en último término, la cobertura de naturaleza y espíritu comprende ambas suertes de intereses y determina el sentido de la conducta al registrar análoga aplicabilidad en la experiencia, de modo que el precitado dualismo subsiste mediante la apreciación esquemática de los valores como elementos tendientes al homólogo cumplimiento de necesidades y deseos, pero la cultura se orienta al progreso del espíritu y persiste más allá de los afanes privativos de la materia. Los intereses comunes que se manifiestan en la vida esfuman la distinción pertinente a motivaciones materiales y espirituales, en similitud al correlativo dualismo constatado en la realidad, pues aunque ambos hemisferios son inescindibles, el distingo de materia y espíritu se diluye en un extenso territorio común donde participan en forma tan estrecha que no puede fjarse con precisión dónde termina la materia y dónde principia el espíritu. Por ello hemos dicho que Ia experiencia está integrada por ese territorio común, pues no hay acto que pudiera presentarse como absolutamente material o netamente espiritual; materia y espiritu coexisten y determinan en conjunto el sentido humano de la vida, con las inflexiones de divergencia y preponderancia que alternativamente caracterizan a las etapas de vida y épocas de la historia.

Existen algunas tendencias radicales a exaltar unilateral y artificialmente uno sólo de los aspectos, en cuyo caso el individuo optaría por cultivar el espíritu como si los afanes de la materia no existiesen, o bien se dedicaría a satisfacer deseos materiales como si los valores se redujeran a una resultante mecánica del condicionamiento biológico. Dichas tendencias son extremistas y violentan la verdadera esencia del hombre, que atiende a la realización armónica de intereses y valores; para refutarla debemos enfatizar que ambos hemisferios actúan de manera conjunta e ineludible, de modo que la consitución material hace acto de presencia en impulsos, tendencias e instintos vinculados a la acción determinista del organismo biológico, en tanto las solicitudes espirituales apuntan de preferencia a la evolución superior cuyos frutos se transmiten a través de instituciones sociales y culturales, ocurriendo de muy distinta manera 
a como se efectúa la transmisión de caracteres biológicos a través de las generaciones.

3. Dualismo y coexistencia. En cualquier caso, importante es notar que los factores de la cultura no operan esencialmente en forma mecánica sino teleológica, y no atienden primordialmente a contenidos materiales sino espirituales, aunque la materia no está ausente de ellos, lo cual auspicia la resultante conjunta del valor. El distingo de civilización y cultura se comprende básicamente por el carácter diferencial de las motivaciones que predominan a cada momento y puede mantenerse con la salvedad de ser relativo, pues no existe diferencia inzanjable ni oposición irreductible en los hemisferios de naturaleza y conducta. Dichas tendencias violentas, cuando son extremas, la verdadera indole del ser humano y para refutarlas debemos enfatizar que los intereses materiales no se producen necesariamente en contra de los espirituales, o viceversa; lo deseable en todo caso es que coexistan, pues la constitución del ser humano está integrada por materia y espíritu, de modo que el distingo no significa oposición irreductible sino complementación recíproca, análogamente a como los miembros de un organismo son diferentes pero compatibles y participan armónicamente en el cumplimiento de una función común.

A partir de esa ingénita dualidad se explica la existencia de valores $\mathrm{e}$ intereses en las alternantes demandas materiales y espirituales; ambas formas de experiencia son inescindibles y sus respectivas motivaciones- se vieren al cúmulo de requerimientos que plantean civilización y cultura, mutuamente estimuladas para justificar un sentido progresivo. En la cultura se reafirma la aspiración suprema a exaltar los designios del espíritu, mientras la civilización auspicia el progreso material en ciencia, técnica e industria, tendiendo a elevar el nivel de vida en las comunidades para hacerla más segura y confortable.

Esto es lo que se comprueba desde épocas remotas con el simultáneo desplante de recíprocos intereses que saturan el ámbito de nuestro ser individual y colectivo; la preocupación por sobrevivir o vivir cada vez mejor refleja la tendencia materialista que se prolonga al cúmulo de requerimientos adicionales y se constata originalmente en necesidades o deseos. Es fácil notar la demanda de seguridad refrendada a través del tiempo en forma de comodidad y placer; la urgencia de sobrevivir se transforma en el anhelo de vivir mejor y procurar una situación que además de confortable sea placentera, la cual se hace más sofisticada a medida que transcurre la evolución y torna ostentosa e incluso afrentosa cuando el esfuerzo de la comunidad arroja productos que se desvirtúan en agravio del hombre, recursos materiales que se concentran en exceso, motivando un alto grado de injusticia social; esto es lo que se 
contempla actualmente en la civilización moderna exacerbada por el frenesi materialista que acompaña al desbordado afán de ostentación y poder.

La prevalencia material obedece al deshumanizado pragmatismo de nuestro tiempo, aunque mejor sería reconocer que el exagerado afán utilitario se constata desde siempre y exhibe diferentes modalidades en cada época, según el tipo de valores adoptados y las obras en que se realizan; así irrumpió desde que la humanidad logró dominar los obstáculos que presenta la naturaleza para ponerla a su servicio e incrementar sus. deseos de mejoramiento, en lo cual estriba el resorte promotor del progreso. Esta observación introduce de lleno al cúmulo de aspiraciones utilitarias que inspiran el avance de la historia y replantean constantemente la demanda de proseguir el irrevocable designio de superación de acuerdo al nivel de adelanto registrado en cada época.

4. Antigüedad de la cultura. Desde los tiempos más remotos se advierte una estrecha comunidad de intereses mediante la producción deactos y objetos que cumplen ambas funciones en la vida cotidiana; los productos del hombre prehistórico denotan el empeño pragmático de aprovechar los recursos disponibles y acoplarlos a la función decorativa con formas y ornamentos que reciben al ser creados, cuya finalidad consiste en motivar complacencia a la vez que desempeñan utilidad. Semejante tipo de objetos acreditan la gran sensibilidad observada desde un principio en las expresiones humanas por lo cual el valor estético de los. utensilios prehistóricos es inmarcesible, aunque el aprovechamiento utilitario haya sido ampliamente superado. A ello se debe que el arte de remotas épocas reciba un ferviente reconocimiento de la posteridad y se extienda hasta nuestros días, con la acendrada conciencia de su significado; se trata de un tributo de admiración comparable al que ameritan las obras maestras del arte académico. Tales objetos denotan no sólo el carácter de instrumentos prácticos, sino también de obras hermosas quecomplacen la sensibilidad y estimulan el sentido de lo bello; así se desarrollan a través del tiempo, alentando el impulso a contemplar el mundo a través de sus manifestaciones gratas y el deseo de producir cosas. bellas, además de útiles.

También se advierte la presencia de una filosofía implícita en la concepción estética, incluyendo cierto tipo de axiología, pues el hombre sabe valorar sus finalidades y la forma de obtenerlas, aunque al principio no tuviese cabal conciencia de sus actos ni del destino que la historia depararía a sus espontáneas creaciones. Por ello se reconoce el carácter altamente creativo de las civilizaciones primitivas, cuya origen acota el remoto surgimiento que en ellas encuentra la actividad cultural; también el desarrollo que experimentan en épocas postreras, de modo que valen 
no sólo por lo que logran en sí mismas, sino por lo que permiten obtener a ulteriores generaciones. La sensibilidad perceptiva del hombre primitivo dejó profunda huella en los utensilios cotidianos, pero el espíritu creativo que en ellos se advierte es de índole fundamentalmente estética y su evolución se logra en el orden espiritual, aunque en un principio dependa del impulso material para arbitrar un equipo de satisfactores a la vez prácticos y deleitosos. Así se lleva a cabo la fecunda simbiosis de materia y espíritu, de la cual deriva una de las convicciones básicas que figuran en el basamento de la cultura, consistente en la prolongación y superación de la vida; los instrumentos arcaicos dan testimonio de civilización y exhiben definidos rasgos de aptitud cultural, polarizando la necesidad de combinar las creaciones del espíritu con la vocación de utilizarlos para su beneficio; este hecho señala el origen del humano desarrollo en el desplante de civilización y cultura.

Vemos pues, cómo desde las épocas más remotas se evidencia el paralelo de sensibilidad y expresión, conocimiento y técnica, arte y utilidad; la pintura de las cavernas constituye elocuente prueba de la temprana sensibilidad que poseía el hombre prehistórico al captar e interpretar las imágenes provenientes del entorno vital, con la habilidad necesaria para plasmarlas de modo que fuesen prácticamente imperecederas. El testimonio fehaciente de su aguda intuición se encuentra en la manera como percibió formas y contornos, con el acopio de colores que han persistido a través de milenios, todo lo cual configura un trabajo efectuado de manera tan espléndida que a pesar de su primitivismo, o precisamente por él, constituye el primer tesoro pictórico de la humanidad; allí se acogen valores culturales tan selectivos como los de cualquier obra de arte, al punto que las creaciones del hombre prehistórico se califican de magistrales y se incluyen en la bibliografía del arte universal.

5. Progreso permanente. El procedimiento empleado no sería tan sencillo ni espontáneo como parece indicarlo su reflejo perceptivo; la técnica que permitió una prevalencia indeleble al pasar del tiempo debió ser producto de prolongada secuela de observaciones y experiencias que incluyeron la selección de materiales cuya certera aplicación hizo posible que trazos y colores persistieran a través de siglos y milenios, de modo que una gran habilidad acompaña a la sensibilidad del hombre primitivo y se revela en la índole pictórica de sus obras, traduciendo el cúmulo de valores que han llegado hasta nosotros como testimonio de la humana creatividad. Civilización y cultura acusan un mismo origen, pero se diversifican por la alternante revelancia de valores materiales y espirituales, en medio de la simultánea tendencia a fundirse en un mismo propósito que es la exaltación de lo humano.

El valor está presente en todas las formas de vida y denota un simul- 
táneo desarrollo mediante el conocimiento dedicado en apoyo de sus motivaciones, por lo cual el estudio sistemático de la evolución es objeto de los más amplios análisis que proveen principalmente ciencias como antropología, sociología e historia, denominadas genéricamente ciencias del hombre, en las cuales se advierte una clara proclividad a fundar la conceptuación axiológica de los procesos sociohistóricos. A través de dichas ciencias se comprende el avance de la humanidad en paralelo a la génesis de sus motivaciones; sabemos que al iniciarse la vida sedentaria despuntan las actividades culturales con el cultivo de los valores; no es mera coincidencia que cultura y agricultura emparenten en su origen fáctico y semántico, pues el cultivo de la tierra obedece al mismo interés originario que el cultivo del hombre, consistente en desarrollar la actividad, sólo que la agricultura concierne a la productividad material, mientras la cultura atiende a la productividad espiritual y se denomina creatividad.

La evolución de los intereses y la forma de satisfacerlos se verifica integramente en el saber que acompaña a las manifestaciones de vida; la posesión del conocimiento repercute en la posibilidad de valorar con el ejercicio de criterios apoyados en nociones obtenidas con relación a su significado. El conocimiento de los fenómenos naturales empieza a manifestarse elementalmente en la correspondencia que adquieren frente a los intereses prácticos; saber cómo operan los hechos de la naturaleza es indispensable para prevalecer en ellos y vencer los obstáculos que presentan, de modo que el interés precursor de la cientificidad germina bajo el incentivo del conocimiento e impulsa las primeras posibilidades de evolución. El origen de la cultura se ve acompañado por el saber y se reviste con un ropaje de utilidad; más tarde se buscarán leyes que expliquen las causas de lo observado, pero ante la imposibilidad a responder de manera inmediata a los interrogantes planteados, el hombre incuba creencias y supersticiones encubiertas bajo el sugerente ropaje de mitologías, cosmogonías y religiones, que constituyen el umbral de la cultura y evolucionan similarmente a las demás formas de vida, incluyendo en primer término el conocimiento que abre la compuerta a los ensayos precursores de ciencias y filosofía.

Desde entonces se produce una verdadera catarata de ensayos o conjeturas cuya adelantada modalidad se externa en pensamientos e investigaciones que alcanzan superior nivel en la madurez củltural, como fruto de la evolución que marcha en forma ininterrumpida, aunque a veces irregular y accidentada; así lograron desentrañarse los procesos naturales mediante experimentos que permiten conocerlos y modificarlos para asumir el control de sus causas; uno de los signos de madurez radica en que las ciencias promueven la resolución de los problemas básicos me- 
diante diversas teorias que participan alternativamente del planteamiento universal tradicionalmente adjudicado a la filosofía. Nos encontra. mos ahora en avanzada etapa del saber donde los problemas filosóficos enlazan con los cientificos y auspician un trabajo interdisciplinario que eleva a su más alto nivel las motivaciones originales del pensamiento; el constante desarrollo de filosofía y ciencias auspicia el advenimiento de nuevas respuestas para esclarecer viejos problemas, invariablemente apoyados en el saber conjunto que constituye el universal receptáculo filosófico y científico.

De este modo se constata el progreso del conocimiento en homología con el desarrollo de civilización, cultura, ciencia, técnica y valor; para avanzar en el camino, la primera condición que debe cumplirse estriba en conocer los intereses y la manera de satisfacerlos, poniéndolos al servicio del hombre, lo cual equivale a saber cómo son y cómo deben ser, pues de lo contrario sería imposible definir el sentido de la acción que garantiza su cumplimiento y refrenda la necesidad de renovarlos, en donde está cifrada la dinámica de vida. Interesa destacar en todo ello que la prosecución de valores se lleva a cabo como signo del progreso, por lo cual el adelanto en la cultura se constata paralelamente al desarrollo del saber en general y se acopla a los diversos grados de civilización; el conocimiento representa la vía de acceso para adquirir conciencia axiológica de la existencia y se vierte a la concepción y realización de valores, con la recíproca funcionalidad que desempeñan para orientar el sentido direccional de la actividad. El conocimiento ocurre a través de conceptos sistemáticamente polarizados en teoría y práctica, cultura y civilización, amalgamados en el vértice de la conciencia axiológica que logra apreciable madurez como autoconciencia filosófica, cuyo basamento sincrético estriba en el saber universal proyectado a la experiencia y expresado en términos de valor.

6. Desfasamiento del progreso. El progreso de la humanidad se registra en forma constante, pero no uniforme, pues sus hemisferios no evolucionan con igual ritmo ni persiguen el mismo tipo de motivaciones; puede afirmarse que los intereses materiales predominan de hecho sobre los espirituales, aunque estos prevalecen de derecho sobre aquéllos. Es fácil comprobar que mientras se registran pasmosos adelantos' en ciencia y técnica, no se advierte lo propio en el reino de la cultura, cuyas disciplinas difícilmente alcanzarian un nivel comparable al que denota el avance tecnológico de nuestro tiempo. Se han obtenido realizaciones materiales de insospechada magnitud que hasta hace poco parecían inverosímiles, pero no se reconocen análogos progresos en el campo del espíritu, e inclusive es lícito dudar que existan auténticos avances en ese campo, teniendo a la vista las acciones de insólita barbarie que persisten 
bajo el imperio de espurios intereses y primitivos instintos; parece como si en algunos aspectos la humanidad se encontrara en retroceso con respecto a las etapas de su pristinidad surgiente, a cuyo efecto suele citarse prototípicamente la excelsa afloración del clasicismo como signo de insuperable madurez en la cultura universal.

Agresión, destrucción, desolación y explotación siguen siendo un modo generalizado, aunque a veces socialmente reprimido de ser y vivir; los instintos amenazan desbordarse en forma bestial y no faltan pruebas de la facilidad con que se llega a insospechados extremos destructivos. Sería difícil precisar si el hombre es intrínsecamente mejor o peor que antaño, pero es indudable que ahora exhibe un grado de peligrosidad infinitamente superior debido al ominoso empleo de grandes recursos con fines de dominio y destrucción; el torcido destino que se confiere a portentosos descubrimientos ha hecho que el hombre sea hoy más peligroso que nunca y su instinto depradador amenaza convertirlo en destructor de la naturaleza y de sí mismo; obvio es que los mortíferos artefactos bélicos poseen ahora un poder infinitamente mayor de lo que pudo concebir la imaginación más exaltada en su libre fantasía.

Así como el progreso material producido por el hombre se vuelve en contra del hombre mismo, vemos también como el extraordinario auge tecnológico e industrial destinado a mejorar los sistemas de vida lesiona severamente la ecología y el desarrollo económico asume nuevos perfiles a través de industria, comercio y banca, en creciente conducción monopólica que propicia mayores injusticias a la vez que disminuye oportunidades a las mayorías. El desarrollo de la inteligencia degenera en híbrido maridaje con el instinto de dominio y en vez de dignificarla provoca su degradación al infundirle ominosa capacidad destructiva; la exacerba. ción de poder desvirtúa los valores hasta el punto de confundir la conciencia axiológica de la humanidad con una perspectiva donde resulta difícil distinguir el bien y el mal. Estas serían algunas de las negativas consecuencias que han sido paradójicamente provocadas por el portentoso adelanto científico y tecnológico, en acerbo contraste con el rezago en la cultura, todo lo cual repercute en ostensibles signos de inevitable decadencia que se han atribuido primordialmente a Occidente pero quizá Io sean para toda la humanidad.

Tales signos permiten afirmar, cuando menos, que existe un grave desfasamiento en el adelanto de la civilización frente al rezago en la cultura; por ello contrasta el prodigioso avance científico y tecnológico frente al estancamiento del humanismo, al punto de que poco o nada ha avanzado sustancialmente desde la antigüedad, si tenemos en cuenta la madurez alcanzada por el hombre en doctrinas y actitudes humanistas, cuando por vez primera fueron postulados los ideales en calidad de valo- 
res supremos y permanentes; por ello es frecuente clamar por el retorno a los principios de la antigüedad clásica, como parece indicarlo el conocido adagio que mueve a la más profunda consideración axiológica de la historia: todo tiempo pasado fue mejor.

7. Sindrome de nuestro tiempo. El cúmulo de negativas preculiaridades que se contemplan por doquier han hecho imprescindible acudir a ellas cuando se trata de precisar el perfil de la época que vivimos, y aunque no sean exactamente privativas en ella, el hecho es que ahora se confrontan a nivel más riesgoso de lo que jamás fueron en el pretérito. Así se denuncia repetidamente que el progreso material se ve acompañado por fuertes intereses y promueve la explotación del hombre por el hombre como antivalor prototípico de la civilización en contra de la cultura. El sojuzgamiento de la dignidad humana repercute en atropello de sus valores y el inequitativo desarrollo socioeconómico refleja la injusticia imperante en nuestro tiempo; la abundancia de recursos se concentra en exiguas minorías frente a la miseria que posterga a la gran mayoría de la humanidad; explotación e ignorancia se mantienen como instrumento de dominio, todo lo cual determina que, hoy como ayer, el hombre deba ser postrado a fin de ser dominado; he aquí el execrable pero realista apotegma que sintetiza la esencia del sindrome contemporáneo.

Hemos descrito algunos de los elocuentes rasgos que muestran al hombre como eterno lobo del hombre, aunque la explotación se recubra con un barniz de civilización; la conciencia que de ello existe se confunde con los reciamos de conjurarla, de modo que explotación y dominio se presentan como negativos acompañantes del progreso. Se admite que es necesarịo promover el reconocimiento de los valores vigentes sin omitir que se han hecho defectivos, en la medida que la actividad del espíritu se rezaga ante el avance inconmensurable del progreso material, con los inconvenientes ampliamente reconocidos como acompañantes ineludibles en el sindrome de nuestro tiempo. Necesario es detenerse a examinarlo para ubicar los valores que debemos asimilar o realizar, como paso previo al impulso renovador que constituye el umbral del progreso; en ello se requiere un concienzudo manejo de la óptica axiológica donde se refleja el abigarrado espectro de la evolución histórica calidoscópicamente polarizada en sus diversas modalidades de valor.

Así se comprende por qué resulta de extraordinaria importancia llevar a cabo el análisis comparativo del devenir histórico que ofrece la axiología, de consuno con la filosofía de la historia y las ciencias del hombre; afocar el decurso evolutivo de la realidad humana en su acaecer temporario y acceder a la conciencia axiológica entendida como instrumento filosófico, cientifico y cultural constituye una de las ineludibles preocu- 
paciones de individuo y colectividad. También representa el núcleo del saber humano, aplicable a la excogitación de valores, en lo cual radica la aplicabilidad concreta de nuestra disciplina. El requerimiento primordial de este análisis consiste en evaluar el panorama que deparan civilización y cultura como formas permanentes, pero al mismo tiempo cambiantes de vida, contemplado a través del universo axiológico y explicado mediante el criterio hermenéutico del valor, todo lo cual equivale a reconocer la vida como prístino hontanar de creación y evolución, mediante el apoyo que proporciona una clara conciencia de los valores en ella desenvueitos y aplicados a ella misma para bien de la humanidad. 